\title{
Have the Causes of Revision for Total and Unicompartmental Knee Arthroplasties Changed During the Past Two Decades?
}

\author{
Gro S. Dyrhovden MD, Stein Håkon L. Lygre PhD, Mona Badawy MD, PhD, \\ Øystein Gøthesen MD, PhD, Ove Furnes MD, PhD
}

Received: 14 October 2016/Accepted: 7 March 2017/Published online: 15 March 2017

(C) The Association of Bone and Joint Surgeons \& 2017

\begin{abstract}
Background Revisions after knee arthroplasty are expected to increase, and the epidemiology of failure mechanisms is changing as new implants, technology, and surgical techniques evolve.

Questions/purposes (1) Was there improvement in survival for TKA and unicompartmental knee arthroplasty (UKA) when comparing two consecutive 11-year periods with similar followups in a national registry? (2) Were there changes in the causes of revision during the two times? (3) Could the changes in revision causes be attributed to patient or implant characteristics?

Methods A total of 60,623 TKAs (2426 revisions) and 7648 UKAs (725 revisions) were selected from the Norwegian Arthroplasty Register and analyzed based on year
\end{abstract}

Each author certifies that neither he or she, nor any member of his or her immediate family, have funding or commercial associations (consultancies, stock ownership, equity interest, patent/licensing arrangements, etc) that might pose a conflict of interest in connection with the submitted article.

The Norwegian Arthroplasty Register is financed by the Western Norway Regional Health Authority (Helse-Vest) (GSD).

All ICMJE Conflict of Interest Forms for authors and Clinical Orthopaedics and Related Research ${ }^{\mathbb{R}}$ editors and board members are on file with the publication and can be viewed on request.

Clinical Orthopaedics and Related Research ${ }^{\mathbb{R}}$ neither advocates nor endorses the use of any treatment, drug, or device. Readers are encouraged to always seek additional information, including FDAapproval status, of any drug or device prior to clinical use.

Each author certifies that his or her institution approved the human protocol for this investigation, that all investigations were conducted in conformity with ethical principles of research, and that informed consent for participation in the study was obtained.

This work was performed at the Norwegian Arthroplasty Register, Department of Orthopaedic Surgery, Haukeland University Hospital, Bergen, Norway. of primary surgery: 1994 to 2004 (Period 1) and 2005 to 2015 (Period 2). TKAs had median followup of 3.5 years in Period 1 and 4.2 years in Period 2. Median followup for UKAs was 2.7 years in Period 1 and 4.6 years in Period 2. Of the patients included in the registry, $99.6 \%$ were accounted for at the time of analysis, whereas $0.4 \%$ had moved abroad. We used Kaplan-Meier analyses and logrank test to investigate changes in survival. Relative risk of revision in Period 2 relative to Period 1 was calculated for each registered revision cause in a Cox regression model adjusted for age, sex, diagnosis, fixation, and patella resurfacing.

Results For TKAs, the 10-year Kaplan-Meier survival free from revision improved from Period 1 to Period 2 from $91 \%(95 \%$ CI, 90\%-92\%) to $94 \%$ (95\% CI, 94\%-95\%; p <

\section{G. S. Dyrhovden $(\bowtie)$, S. H. L. Lygre, O. Furnes}

Norwegian Arthroplasty Register, Department of Orthopaedic Surgery, Haukeland University Hospital, Møllendalsbakken 11, 5021 Bergen, Norway

e-mail: gdyrhovden@gmail.com

G. S. Dyrhovden, M. Badawy, Ø. Gøthesen, O. Furnes

Department of Clinical Medicine (K1), Faculty of Medicine and DentistryUniversity of Bergen, Bergen, Norway

S. H. L. Lygre

Department of Occupational Medicine, Haukeland University

Hospital, Bergen, Norway

M. Badawy

Coastal Hospital in Hagevik, Hagavik, Norway

$\varnothing$. Gøthesen

Department of Orthopedic Surgery, Haugesund Hospital,

Haugesund, Norway 
0.001). Revisions resulting from aseptic loosening of the femoral component, polyethylene wear/breakage, patellar dislocation, and unexplained pain decreased, whereas revisions resulting from early infection increased. Patients in Period 2 were younger and more often men compared with patients in Period 1. A higher risk of revision was found for male sex (relative risk [RR], 1.1; 95\% CI, 1.0$1.2 ; \mathrm{p}=0.048)$ and age younger than 65 years $(\mathrm{RR}, 1.7$; 95\% CI, 1.6-1.9; p < 0.001). With UKAs, the 10-year survival free from revision was $80 \%$ (95\% CI, 76\%-84\%) in Period 1 and $81 \%$ (95\% CI, 79\%-83\%; p = 0.261) in Period 2. Revisions resulting from tibial aseptic loosening, polyethylene wear/breakage, and periprosthetic fractures decreased, but there were more revisions resulting from progression of osteoarthritis. In Period 2, there were more men and the average age was younger than for patients in Period 1. For UKAs, age younger than 65 years had a higher risk of revision (RR, 1.7; 95\% CI, 1.5-2.0; p < $0.001)$, whereas sex did not affect the risk of revision.

Conclusions We found an improvement in survival free from revision for TKA in the last period, but no similar improvement for UKA, and the survivorship for UKAs remains rather dramatically lower than that observed for TKAs. The decision to perform a UKA should be made with the explicit awareness that its survivorship is substantially inferior to that of TKA; any perceived advantages of UKA should be balanced against this issue of its decreased durability.

Level of Evidence Level III, therapeutic study.

\section{Introduction}

Knee arthroplasty is a common and effective treatment in osteoarthritis [67], and the volume of TKA and unicompartmental knee arthroplasty (UKA) is increasing [9, 59]. The demand for primary TKA and revision TKA is expected to increase dramatically in the United States and in England and Wales by 2030 [36, 53]. Patient satisfaction is lower after revisions compared with primary procedures [31, 57], and revisions represent a high cost to patients, hospitals, and society $[6,36]$. To reduce this increasing revision burden, we need to understand the failure mechanisms of knee arthroplasty as new implants and surgical techniques are developed.

National joint registries worldwide have reported infection and aseptic loosening as the most common revision causes in TKA [1, 8, 27, 50, 51, 61, 69], whereas aseptic loosening and progression of osteoarthritis or unexplained pain were most frequent for UKA [1, 51, 61, 69]. A study from the Norwegian Arthroplasty Register (NAR) showed a higher risk of revision resulting from aseptic loosening, periprosthetic fracture, pain, and polyethylene wear for UKAs compared with TKAs [25]. Lombardi et al. [41] reported aseptic loosening, infection, and instability were the main reasons for revision after TKA. Other studies showed a high and increasing number of early revisions in TKA and UKA, with infection as one of the major causes of early TKA revision [21, 64, 65]. However, these studies presented results from a few high-volume centers and studies from national joint registries offer verification of these findings with the advantage of a range of surgeon experience and larger volumes.

We asked the following questions: (1) Were there improvements in survival for TKA and UKA when comparing two consecutive 11-year periods with similar followups in a national registry? (2) Were there changes in the causes of revision in the two times? (3) Could the changes in revision causes be attributed to patient or implant characteristics?

\section{Materials and Methods}

\section{Data Sources}

The NAR covers a population of approximately 5.2 million. The registration completeness is greater than $95 \%$ for primary operations and greater than $89 \%$ for revisions in both periods, calculated on an individual level as percent of operations reported to the Norwegian Patient Registry as described in the NAR annual report [20, 69]. Calculating completeness of reporting of revisions is not straightforward owing to different inclusion criteria and codes to the Norwegian Patient Registry and the Norwegian Arthroplasty Register. We know from audits at single hospitals that especially infections tend to be underreported to the NAR [2]. These operations often are done out of scheduled operating hours and therefore might be forgotten by the operating surgeons. Registration of knee arthroplasties started in 1994 [24]. Revised arthroplasties are linked to the primary operation by using the Norwegian personal identification number. All data are collected from a registration form that is completed immediately after the operation by the surgeon who examined and provided the diagnosis for the patient and performed the knee arthroplasty [23, 69]. For each revised arthroplasty, several causes of revision can be registered.

Between 1994 and 2015, 68,648 primary knee arthroplasties were reported to the NAR. Hinged, bicompartmental (UKA with a patellar component), and patellofemoral joint replacements were excluded owing to low numbers. Finally, 60,623 TKAs (2426 revisions) and 7648 UKAs (725 revisions) were selected for analysis (Fig. 1). Two times, referring to the primary procedure, were chosen for comparison of revision causes: 1994 to 2004 (Period 1) and 2005 to 2015 (Period 2). TKA had median followup of 3.5 years in 
Fig. 1 An overview of patient selection is shown. *3384 were patella resurfaced; ${ }^{\dagger} 1213$ were patella resurfaced; NAR $=$ Norwegian Arthroplasty Register

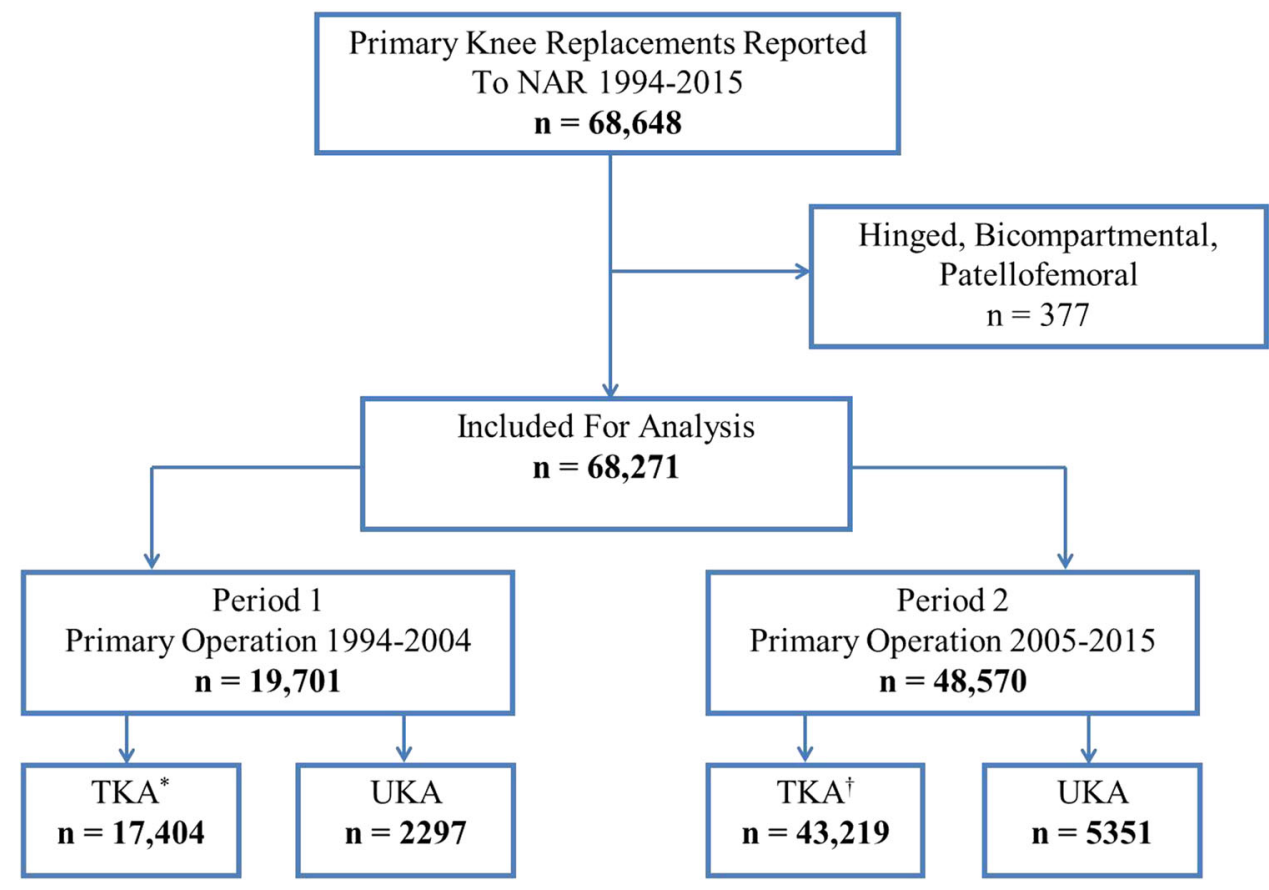

Period 1 and 4.2 years in Period 2. Median followup for UKA was 2.7 years in Period 1 and 4.6 years in Period 2 (fewer UKAs were performed during the early portion of Period 1) Revision was defined as removal, exchange, or addition of one or more prosthesis components (including exchange of a polyethylene insert or addition of a patellar component in a patella nonresurfaced TKA). Only the first revision was included for arthroplasties with multiple revisions. For arthroplasties with multiple revision causes reported, the main cause of revision was determined based on the hierarchy from the Australian Orthopaedic Association National Joint Replacement Registry (AOANJRR) [1]. For the revision diagnosis "unexplained pain," no other reason for revision was registered.

\section{Statistics}

TKAs and UKAs were analyzed separately. Differences in demographic data were calculated by Pearson chi-square test and Student's t-test. Median time of followup in the groups was estimated by the reversed Kaplan-Meier method. We also analyzed the differences in a competing risk model to ensure that differences in deaths or emigrations in the groups did not affect the results [22]. Implant survival was estimated by a Kaplan-Meier analysis at 10 years followup in each group with censoring at the time of death, emigration, or at the end of followup. The log-rank test was used to find differences in survival and a risk estimate was calculated in an unadjusted Cox regression model. All arthroplasties in Period 1 were censored December 31, 2004, and arthroplasties in Period 2 were censored December 31, 2015, to get two times of 11 years followup. Information regarding deaths and emigrations was obtained from the National Population Register. The Cox multiple regression model was used to calculate relative risk of revision (RR) in Period 2 relative to Period 1 for each revision cause according to the hierarchy, adjusted for age (continuous), sex, diagnosis (osteoarthritis/other), fixation (cemented/uncemented/hybrid), and use of a patellar component (yes/no). The proportional hazards assumption (PH) of the Cox regression models was assessed by tests and inspection of Schoenfeld residuals [58].

For revision causes where the $\mathrm{PH}$ failed, further investigations were performed for separate followup intervals. Cut-points were decided based on tests and visual inspection of the Schoenfeld residuals and were set individually for each revision cause until the $\mathrm{PH}$ was fulfilled.

All tests were two-sided and the statistical significance level was set at 0.05 . Statistical analyses were performed using IBM SPSS Statistics Version 22.0 (IBM Corporation, Armonk, NY, USA) and R Version 3.3.0 (The R Foundation, Vienna, Austria).

\section{Results}

Ten-year Survival Free From Revision

\section{$T K A$}

With TKA, 10-year survival improved from Period 1 to Period 2. The 10-year survival rate was $91 \%$ (95\% CI, 
90\%-92\%) in Period 1 and 94\% (95\% CI, 94\%-95\%; p < 0.001) in Period 2 (Fig. 2). The RR of revision in Period 2 versus Period 1 was 0.8 (95\% CI, 0.7-0.8; $\mathrm{p}<0.001)$. The proportion of deaths was $14 \%$ in Period 1 and $9 \%$ in Period 2 , but analyses including death as a competing risk did not change the RR estimate. For the risk estimate, the PH was not fulfilled; Period 2 had an increased risk of revision the first 1.5 months (RR, 2.8; 95\% CI, 1.9-4.0; p < 0.001), but a lower risk of revision greater than 6 months after the operation (Fig. 3). Period 2 showed improved RR of revision for cemented ( $\mathrm{RR}, 0.7 ; 95 \% \mathrm{CI}, 0.7-0.8 ; \mathrm{p}<$ $0.001)$ and hybrid TKA (RR, 0.6; 95\% CI, 0.4-0.8; p = 0.002 ) but not for uncemented TKA (RR, 0.7; 95\% CI, 0.4 $1.1 ; \mathrm{p}=0.140)$.

\section{$U K A$}

Ten-year survival was not improved from Period 1 to Period 2 in UKA. In Period 1, 10-year UKA survival was 80\% (95\% CI, 76\%-84\%) and 81\% (95\% CI, 79\%-83\%; p $=0.261$ ) in Period 2 (Fig. 4). The RR of revision in Period 2 relative to Period 1 was 0.9 (95\% CI, 0.8-1.1; p = 0.3). The proportion of deaths was $8 \%$ in Period 1 and $5 \%$ in Period 2, and the RR estimate was similar in a competing risk model.

\section{Changes in Revision Causes}

$T K A$

TKAs showed a decrease in revisions owing to aseptic loosening of the femoral component, patella dislocation, polyethylene wear/breakage, and unexplained pain and an

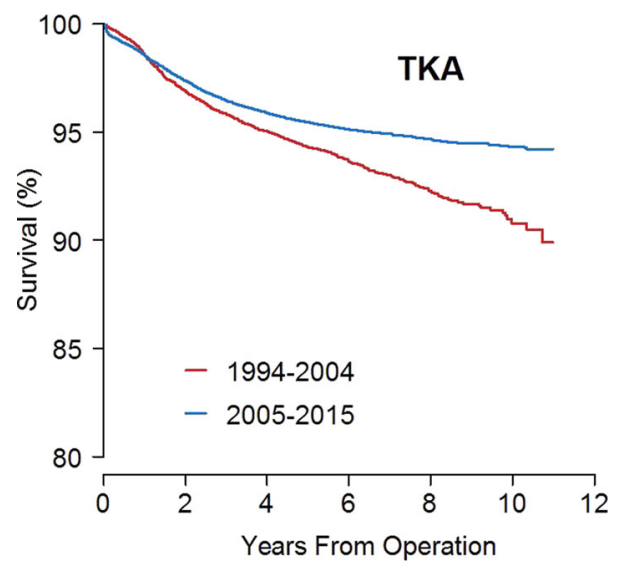

Fig. 2 The Kaplan-Meier curve shows the implant survival during each period for TKAs. Log-rank test: $p<0.001$. Ten years at risk 1994-2004: $\mathrm{n}=495 ;$ 2005-2015: $\mathrm{n}=1956$. increasing risk of early revisions resulting from infection. Risk of revision resulting from loosening of the femoral component was reduced in Period 2 (RR, 0.3; 95\% CI, 0.1$0.4 ; \mathrm{p}<0.001)$, and the results were similar if only cemented implants were included (RR, 0.3; 95\% CI, 0.10.6; $\mathrm{p}<0.001$ ) (Fig. 5). The risk of loosening of the tibial component was not changed when analyzing all fixation methods or cemented implants only. For uncemented and hybrid implants, the results were uncertain owing to low numbers of revisions in each subgroup. The risk of revision resulting from patella dislocation was reduced in Period 2

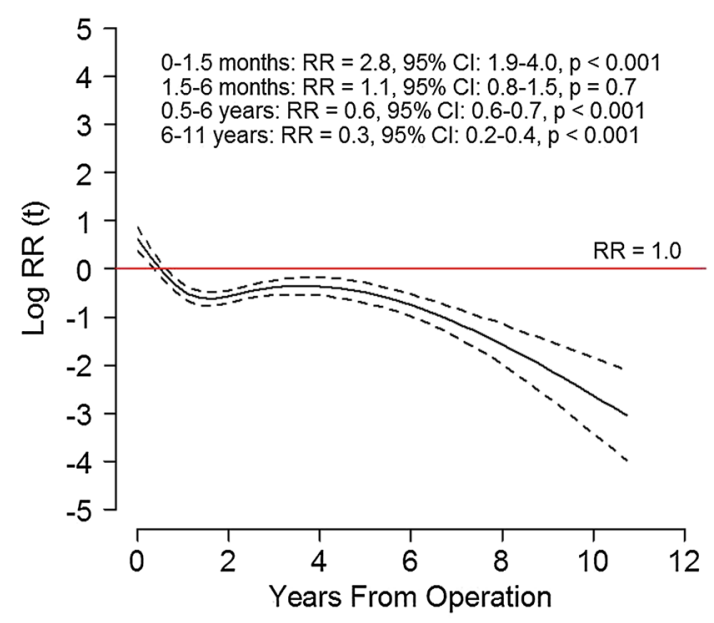

Fig. 3 The risk of revision during 2005 to 2015 (solid black line) with 95\% CI (dotted lines) relative to 1994 to 2004 (red lines) in overall revisions for TKA are shown. The horizontal red line indicates no difference in risk of revision (relative risk [RR], 1). The curves and estimates are adjusted by age, sex, diagnosis, fixation method, and use of patellar component. The RR estimates are divided in intervals to fulfill the proportional hazard assumption.

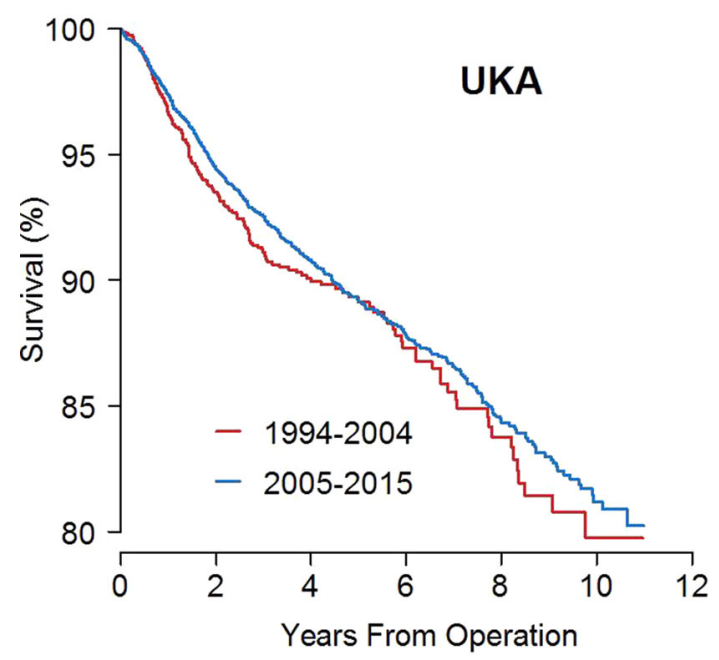

Fig. 4 This Kaplan-Meier curve shows the implant survival during each period for UKAs. Log-rank test: $p=0.261$. Ten years at risk 1994-2004: $\mathrm{n}=59$; 2005-2015: $\mathrm{n}=302$. 


Missing
Infection
Malalignment
Aseptic loosening femur and tibia
Aseptic loosening femur
Aseptic loosening tibia
Aseptic loosening patella
Polyethylene wear*
Dislocation (not patella)
Patella dislocation
Instability
Periprosthetic fracture
Progression of osteoarthritis
Arthrofibrosis
Unexplained pain
Other

$\begin{array}{rr}\begin{array}{r}\text { Number of } \\ 1994-\end{array} & 2005- \\ 2004 & 2015 \\ 18 & 4 \\ 143 & 438 \\ 51 & 185 \\ 20 & 49 \\ 26 & 25 \\ 97 & 245 \\ 9 & 2 \\ 38 & 12 \\ 16 & 17 \\ 28 & 20 \\ 59 & 246 \\ 15 & 35 \\ 1 & 21 \\ 13 & 64 \\ 213 & 218 \\ 40 & 58\end{array}$

Fig. 5 The number of revisions, relative risk (RR, 1994-2004 is the reference), and 95\% CI for each revision cause for TKAs are shown. An RR less than 1 indicates a lower risk of revision during 2005 to 2015 relative to 1994 to 2004 . ${ }^{*}$ The proportional hazard assumption is

(RR, $0.3 ; 95 \% \mathrm{CI}, 0.2-0.51 ; \mathrm{p}<0.001$ ). The risk of revision resulting from malalignment, dislocation, instability, and periprosthetic fracture was unchanged (Fig. 5). The PH assumption for risk of revision resulting from infection, polyethylene wear/breakage, and unexplained pain was not fulfilled. Risk of revision resulting from infection was increased in Period 2 during the first 6 months with the highest risk within the first 6 weeks (RR, 5; 95\% CI, 3-9; p $<0.001)$. At greater than 1 year postoperatively, the risk of revision resulting from infection was decreased in Period 2 with a RR of 0.6 (95\% CI, 0.4-0.8; p < 0.001) (Fig. 6A). The risk of TKA revision resulting from polyethylene wear/breakage was similar in the two periods at 0 to 2 years, but lower in Period 2 for revisions occurring at 2 to 11 years (RR, 0.02; 95\% CI, 0.005-0.1; p < 0.001) (Fig. 6B). Revisions resulting from unexplained pain were reduced in Period 2 with a RR of $0.3(95 \%$ CI, $0.2-0.4$; $p<$ $0.001)$ for revisions occurring at 0 to 5 years and $0.08(95 \%$ CI, $0.04-0.2 ; \mathrm{p}<0.001)$ for revisions 5 to 11 years postoperatively (Fig. 6C).

\section{$U K A$}

UKAs had fewer revisions resulting from aseptic loosening, polyethylene wear/breakage, and periprosthetic fractures, but more revisions resulting from progression of arthrosis in Period 2. The risk of revision resulting from aseptic loosening decreased in Period 2 with a RR of 0.5 (95\% CI, 0.3-0.8; $\mathrm{p}=0.002$ ) for the femoral component

$\begin{array}{rr}95 \% \mathrm{Cl} & \text { p value } \\ & \\ 1.0-1.5 & 0.031 \\ 0.9-1.8 & 0.13 \\ 0.4-1.3 & 0.35 \\ 0.1-0.4 & <0.001 \\ 0.7-1.3 & 0.82 \\ 0.04-1.4 & 0.11 \\ 0.06-0.2 & <0.001 \\ 0.2-1.0 & 0.064 \\ 0.2-0.5 & <0.001 \\ 1.0-1.8 & 0.060 \\ 0.5-1.7 & 0.71 \\ 0.9-58.0 & 0.060 \\ 0.8-2.9 & 0.17 \\ 0.2-0.3 & <0.001 \\ 0.3-0.7 & <0.001\end{array}$

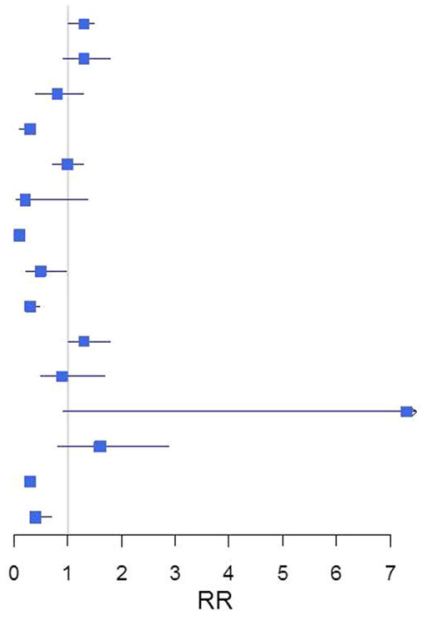

not fulfilled. ${ }^{\dagger}$ Adjusted for age, sex, diagnosis, fixation method, and use of patellar component.

and $0.6(95 \% \mathrm{CI}, 0.4-0.9 ; \mathrm{p}=0.013)$ for the tibial component. Revisions resulting from periprosthetic fractures decreased (RR, 0.3; 95\% CI, 0.1-0.8; $\mathrm{p}=0.017$ ). Revisions resulting from progression of osteoarthritis increased with a $\mathrm{RR}$ of 5 (95\% CI, 2-14; p = 0.002) (Fig. 7). The PH assumption was not fulfilled for the category "polyethylene wear/breakage." Risk of revision resulting from polyethylene wear/breakage was similar at less than 2 years followup, but the risk of revision at greater than 2 years followup was lower in Period 2 with a RR of 0.1 (95\% CI, $0.03-0.2 ; \mathrm{p}<0.001$ ) (Fig. 8). With the numbers available, we found no difference in revisions resulting from infection, malalignment, dislocation, instability, joint stiffness, or unexplained pain (Fig. 7).

\section{Changes in Patient and Implant Characteristics}

\section{TKA}

The average age of patients undergoing TKA was younger in Period 2 and there also were more men in Period 2 compared with Period 1 (Table 1). The risk of revision was slightly increased for men compared with women (RR, 1.1; 95\% CI, 1.0-1.2; p = 0.048). Patients younger than 65 years had a higher risk of revision compared with patients 65 years or older (RR, 1.7; 95\% CI, 1.6-1.9; $\mathrm{p}<0.001)$. Patella nonresurfaced TKAs increased from $81 \%$ in Period 1 to $97 \%$ in Period $2(\mathrm{p}<0.001)$. Cemented implants were used in $87 \%$ of TKAs in Period 1 and $79 \%$ in Period 2. In 

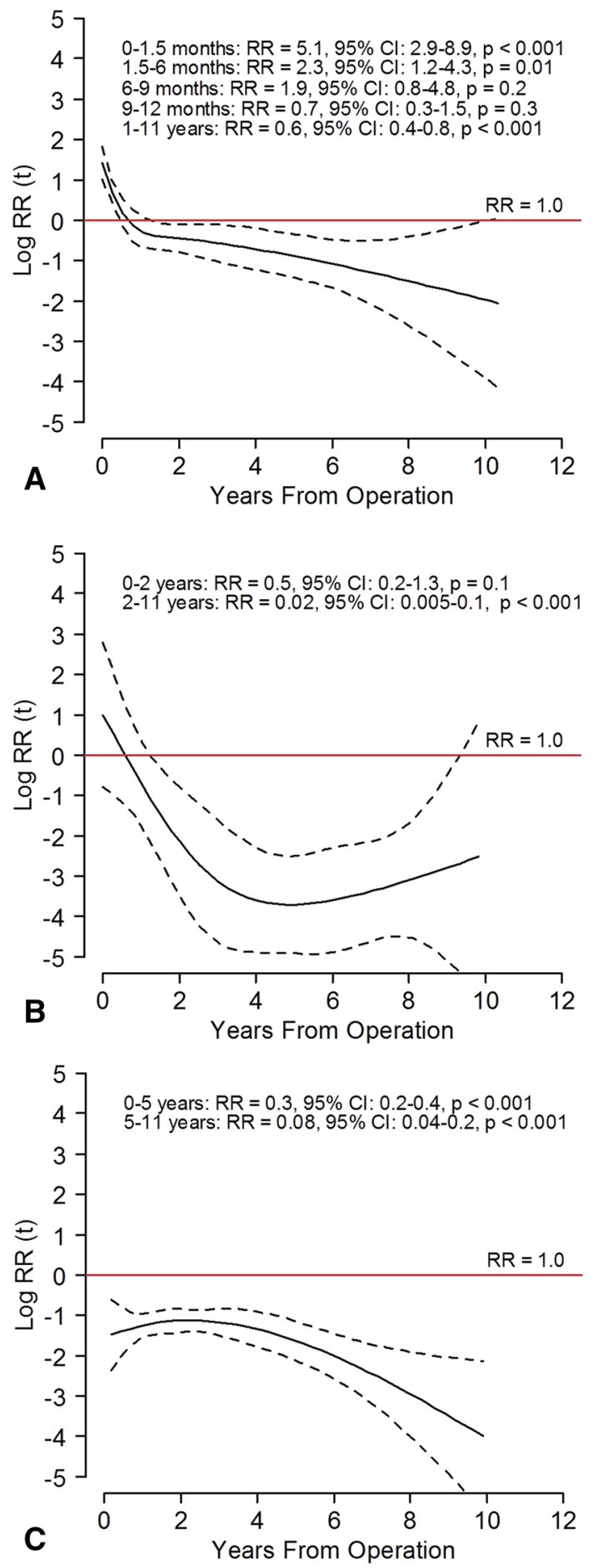

Fig. 6A-C The risk of revision during 2005 to 2015 (solid black line) with $95 \%$ CI (dotted lines) relative to 1994 to 2004 (red lines) in TKAs for (A) infection, (B) polyethylene wear/breakage, and (C) unexplained pain are shown. The horizontal red line indicates no difference in risk of revision (relative risk [RR], 1). The curves and estimates are adjusted by age, sex, diagnosis, fixation method, and use of patellar component. The RR estimates are divided in intervals to fulfill the proportional hazard assumption.
Period 2, there was an increase in the use of uncemented implants (from $2 \%$ to $7 \%$; $p<0.001$ ) and hybrid implants (from $11 \%$ to $13 \%$; $\mathrm{p}<0.001$ ). The cruciate-retaining implant design was most common in both periods $(73 \%$ in Period $1,64 \%$ in Period 2). The use of mobile-bearing implants increased from $26 \%$ in Period 1 to $34 \%$ in Period $2(\mathrm{p}<0.001)$. In Period 1 , the PROFIX ${ }^{\mathrm{TM}}$ cruciate-retaining knee system (Smith \& Nephew, Memphis, TN, USA) (24\%), LCS ${ }^{\circledR}$ mobile-bearing system, DePuy, Warsaw, IN, USA) $(22 \%)$, and GENESIS ${ }^{\mathrm{TM}}$ I cruciateretaining system(Smith \& Nephew) (19\%) were the mostused implants. In Period 2, the PROFIX ${ }^{\mathrm{TM}}$ cruciate-retaining knee system (Smith \& Nephew) $(24 \%)$, LCS $^{\circledR}$ COMPLETE mobile-bearing system (DePuy) (27\%) and NexGen ${ }^{\circledR}$ cruciate-retaining system (Zimmer, Warsaw, IN, USA) $(20 \%)$ were most common, whereas the Tricon $^{\mathrm{TM}}$ (Smith \& Nephew) and GENESIS I ${ }^{\mathrm{TM}}$ (Smith \& Nephew) were not used. The use of AGC Anatomic (Biomet, Warsaw, IN, USA) increased from $1 \%$ to $4 \%$, whereas the use of AGC Universal (Biomet) decreased from $13 \%$ to $2 \%$ in Period 2 (Table 2).

\section{$U K A$}

Patients who underwent UKA had a younger average age and were more often men in Period 2 compared with Period 1 (Table 1). Osteoarthritis was the most common diagnosis in both periods. No implants were uncemented in Period 1, but Period 2 had 66 uncemented implants. The risk of revision was equal for men and women (RR, 1.0; 95\% CI, $0.8-1.1 ; \mathrm{p}=0.5$ ), but age younger than 65 years was associated with a higher risk of revision (RR, 1.7; 95\% CI, 1.5-2.0; $\mathrm{p}<0.001$ ). The Oxford ${ }^{\mathbb{R}}$ Phase 3 (Biomet) was the most-used implant in both periods $(61 \%$ in Period 1, $70 \%$ in Period 2). The Oxford ${ }^{\circledR}$ Partial Knee (Zimmer Biomet) was introduced in 2012 and was the second mostused implant (22\%) in Period 2.

\section{Discussion}

The burden of revision after knee arthroplasty is increasing, and more knowledge regarding revision causes is important to understand failure mechanisms and to prevent future revisions. In this study, we investigated the large cohort from the NAR and asked (1) if there was improvement in survival for TKA and UKA when comparing two consecutive 11-year periods with similar followups at a national level; (2) if there were changes in the causes of revision in the two times; and (3) if the changes in revision causes 


Revision Cause
Missing
Infection
Malalignment
Aseptic loosening femur and tibia
Aseptic loosening femur
Aseptic loosening tibia
Polyethylene wear*
Dislocation (not patella)
Instability
Periprosthetic fracture
Progression of osteoarthritis
Arthrofibrosis
Unexplained pain
Other

$\begin{array}{rr}\begin{array}{r}\text { Number of } \\ 1994-\end{array} & \text { Revisions } \\ 2004 & 2005- \\ 1 & 3 \\ 6 & 35 \\ 9 & 47 \\ 9 & 13 \\ 30 & 55 \\ 36 & 65 \\ 17 & 16 \\ 3 & 23 \\ 6 & 27 \\ 12 & 9 \\ 4 & 83 \\ 2 & 4 \\ 48 & 128 \\ 7 & 27\end{array}$

$\begin{array}{rrr}\mathbf{R R}^{\dagger} & 95 \% \mathbf{C l} & \text { p value } \\ & & \\ 1.9 & 0.8-4.6 & 0.14 \\ 1.7 & 0.8-3.4 & 0.17 \\ 0.3 & 0.1-0.8 & 0.015 \\ 0.5 & 0.3-0.8 & 0.002 \\ 0.6 & 0.4-0.9 & 0.013 \\ 0.2 & 0.1-0.4 & <0.001 \\ 2.4 & 0.7-8.0 & 0.16 \\ 1.4 & 0.5-3.4 & 0.51 \\ 0.3 & 0.1-0.8 & 0.017 \\ 5.0 & 1.8-13.7 & 0.002 \\ 0.7 & 0.1-3.8 & 0.67 \\ 0.8 & 0.6-1.2 & 0.26 \\ 1.2 & 0.5-2.8 & 0.70\end{array}$

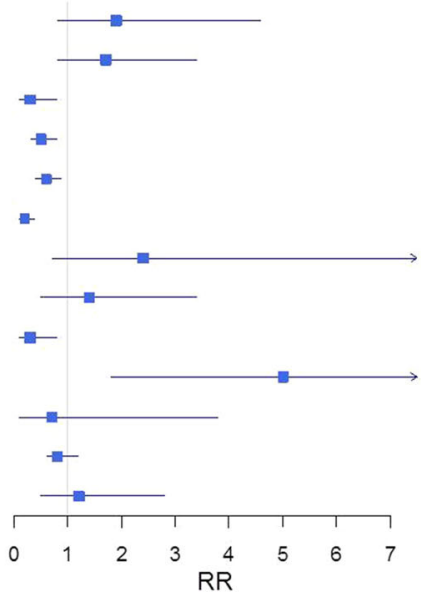

Fig. 7 The number of revisions, relative risk [RR] (1994-2004 is reference), and 95\% CI for each revision cause for UKAs are shown. An RR less than 1 indicates a lower risk of revision during 2005 to 2015 relative to 1994 to 2004 . ${ }^{*}$ The proportional hazard assumption is

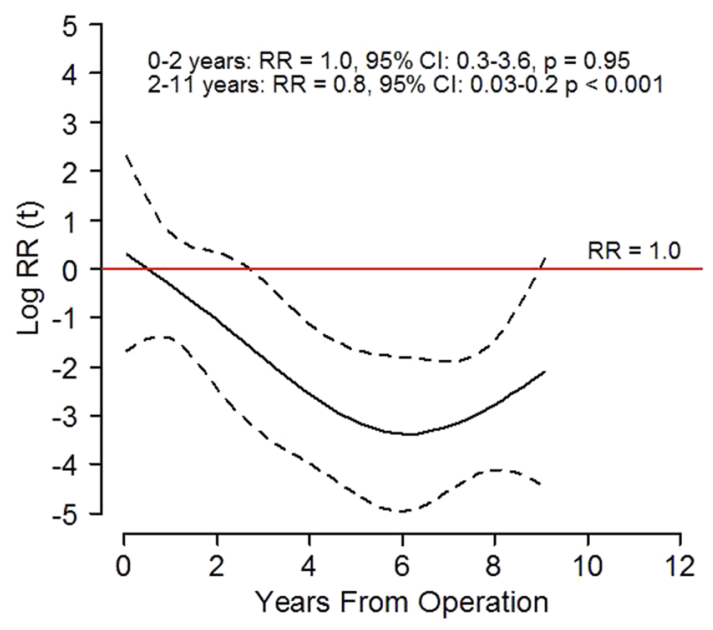

polyethylene wear/breakage, and periprosthetic fractures. Survivorship of UKA remains substantially lower than that observed for TKA, a finding that did not change to any great degree during the periods surveyed.

\section{Limitations}

In this study, the following limitations must be noted. First, the primary endpoint in the NAR is revision. Patients with radiographic failure or unacceptable pain, who for various reasons do not undergo revision surgery, are not recorded in the registry. The true number of failures is uncertain, but a previous study found $72 \%$ survival after 7 years with moderate pain as the endpoint [46]. Second, revision causes in the NAR are registered by the surgeon performing the revision procedure, and each surgeon may classify revision causes differently. Changes in the registration form and awareness of specific revision causes also may change with time and thus affect the results (misclassification bias). For example, "progression of osteoarthritis" was introduced as a separate choice in the NAR registration form in 2011 (for TKA and UKA), and previous revisions for this reason (including late resurfacing of the patella) may have been classified as unexplained pain or other causes. Low-grade infections are difficult to detect [73] and may have been reported as aseptic loosening. Postsurgical stiffness resulting from arthrofibrosis is not well defined and may involve reoperation using only soft tissue procedures without component removal or exchange. Such 
Table 1. Patient demographics

\begin{tabular}{|c|c|c|c|c|}
\hline \multirow[b]{2}{*}{ Patient and implant factors } & \multicolumn{2}{|l|}{ TKA } & \multicolumn{2}{|l|}{ UKA } \\
\hline & 1994-2004 & $2005-2015$ & 1994-2004 & $2005-2015$ \\
\hline Number of cases & 17,404 & 43,219 & 2297 & 5351 \\
\hline Number of revisions & 787 & 1639 & 190 & 535 \\
\hline Mean age of patients at primary operation (years) & 70.5 & 68.7 & 65.6 & 64.5 \\
\hline $95 \% \mathrm{CI}$ & $70-71$ & $69-69$ & $65-66$ & $64-65$ \\
\hline Range & $10-93$ & 13-101 & $25-91$ & $29-93$ \\
\hline Men, $\%$ & 28 & 37 & 38 & 48 \\
\hline \multicolumn{5}{|l|}{ Prosthesis type, n (\%) } \\
\hline Total with patella & $3384(19)$ & $1213(3)$ & NA & NA \\
\hline Total without patella & $14,020(81)$ & $42,006(97)$ & NA & NA \\
\hline \multicolumn{5}{|l|}{ Diagnosis, number (\%) } \\
\hline Osteoarthritis & $13,987(80)$ & $38,304(89)$ & $2035(87)$ & $5027(94)$ \\
\hline Rheumatoid arthritis & $1769(10)$ & $1590(4)$ & $5(0)$ & $9(0)$ \\
\hline Other & $1589(9)$ & $3255(7)$ & $246(11)$ & $303(6)$ \\
\hline Missing & $59(0)$ & $70(0)$ & $11(1)$ & $12(0)$ \\
\hline \multicolumn{5}{|l|}{ Fixation method, number (\%) } \\
\hline Cemented & $15,101(87)$ & $34,231(79)$ & $2263(99)$ & $5241(98)$ \\
\hline Uncemented & $281(2)$ & $3012(7)$ & $0(0)$ & $66(1)$ \\
\hline Hybrid(conventional) & $1959(11)$ & $5777(13)$ & $9(0)$ & $8(0)$ \\
\hline Missing & $63(0)$ & $199(1)$ & $25(1)$ & $36(1)$ \\
\hline \multicolumn{5}{|l|}{ Prosthesis design, number (\%) } \\
\hline Mobile-bearing (cruciate retaining and posterior stabilizing) & $4478(26)$ & $14,555(34)$ & NA & NA \\
\hline Cruciate-retaining & $12,694(73)$ & $27,785(64)$ & NA & NA \\
\hline Posterior cruciate-stabilizing & $74(0)$ & $638(2)$ & NA & NA \\
\hline Constrained condylar knee & $15(0)$ & $113(0)$ & NA & NA \\
\hline Missing & $143(1)$ & $128(0)$ & NA & NA \\
\hline
\end{tabular}

$\mathrm{UKA}=$ unicompartmental knee arthroplasty; NA = not applicable.

operations are not included in most joint registries, and a recent consensus statement suggested that joint registries were not suitable to identify joint fibrosis for this reason [34]. These examples of possible misclassifications could not be accounted for in the analyses of our study. Thus, the results must be interpreted with care, especially in revision causes with low numbers of revisions.

Third, information like radiologic measurements, degree of knee stability, BMI, diabetes, and smoking status are not collected in the NAR, and we were not able to adjust for these or other unmeasured confounders. Comorbidities like insulin-dependent diabetes and obesity are associated with periprosthetic infections [7, 72], and differences in these conditions in the two periods could influence the results of revision resulting from infection. Fourth, a registry study can find associations between registered variables and revision causes but is not able to prove causality [33]. Based on these registry data, we can only theorize why these changes occur. Randomized controlled trials, retrieval analyses, and clinical experiments are needed to explain the changes found in our study. However, the strength of the study is the large sample size and high external validity. Fifth, the number of deaths was higher in Period 1 for patients having TKAs and UKAs. This could lead to a lower survival estimate in Period 1, but analyses including death in a competing risk model did not change the conclusion.

\section{Survival Free From Revision}

Ten-year survival was improved for TKA but not for UKA in the unadjusted analyses, and UKA survivorship continued to lag behind that of TKA during both periods of our survey. The Swedish Knee Arthroplasty Register showed an improvement in 10-year survival from $89 \%$ for TKAs performed during 1985 to 1994 to $96 \%$ during 2005 to 2014, and the 10-year survival rate for UKAs was $86 \%$ 
Table 2. The most commonly used implants during each period for TKA and UKA

\begin{tabular}{|c|c|c|}
\hline Implant & $\begin{array}{l}\text { 1994-2004, } \\
\text { number (\%) }\end{array}$ & $\begin{array}{l}\text { 2005-2015, } \\
\text { number }(\%)\end{array}$ \\
\hline \multicolumn{3}{|l|}{ TKA } \\
\hline PROFIX $^{\text {TM }}$ (Smith \& Nephew) & $4141(24)$ & $10,522(24)$ \\
\hline LCS $^{\mathbb{R}}$ Classic (DePuy) & $3907(22)$ & $532(1)$ \\
\hline GENESIS $^{\mathrm{TM}}$ I (Smith \& Nephew) & $3291(19)$ & $0(0)$ \\
\hline AGC Universal (Biomet) & $2196(13)$ & $923(2)$ \\
\hline Tricon $^{\mathrm{TM}}$ II (Smith \& Nephew) & $1078(6)$ & $0(0)$ \\
\hline Duracon $^{\mathrm{TS}}$ (Stryker) & $599(3)$ & $2153(5)$ \\
\hline NexGen ${ }^{\circledR}$ (Zimmer) & $457(3)$ & $8699(20)$ \\
\hline AGC Anatomic (Biomet) & $159(1)$ & $1569(4)$ \\
\hline LCS $^{\circledR}$ COMPLETE (DePuy) & $97(1)$ & $11,653(27)$ \\
\hline Other & $1479(9)$ & 7168 (17) \\
\hline \multicolumn{3}{|l|}{ UKA } \\
\hline Oxford ${ }^{\circledR}$ Phase 3 (Biomet) & $1404(61)$ & $3745(70)$ \\
\hline GENESIS $^{\mathrm{TM}}$ (Smith \& Nephew) & $326(14)$ & $20(0)$ \\
\hline Miller-Galante (Zimmer) & $220(10)$ & $68(1)$ \\
\hline MOD III (Smith \& Nephew) & $200(9)$ & $0(0)$ \\
\hline Duracon $^{\mathbb{R}}$ (Stryker) & $48(2)$ & $0(0)$ \\
\hline Preservation ${ }^{\mathrm{TM}}$ Unicompartmental Knee System (PEI Surgical) & $35(1)$ & $130(2)$ \\
\hline LINK $^{\circledR}$ Sled (LINK Orthopaedics) & $9(0)$ & $67(1)$ \\
\hline Oxford ${ }^{\mathbb{R}}$ Partial Knee (Zimmer Biomet) & $0(0)$ & $1189(22)$ \\
\hline Other & $55(2)$ & $132(3)$ \\
\hline
\end{tabular}

$\mathrm{UKA}=$ unicompartmental knee arthroplasty.

during 2005 to 2014 [61]. The New Zealand Joint Registry reported 10-year survival of $96 \%$ for TKA and $89 \%$ for UKA, which is somewhat higher than our findings [51]. A high hospital procedure volume is correlated to higher implant survivorship [40, 45]. In Norway, there has been an increase in TKAs and UKAs performed in high-volume hospitals since 1994, and these hospitals have shown a lower risk of revision [4, 5]. From 2000, there has been an increase in the number of hospitals with an annual UKA volume greater than 21 , but also an increase in the number of hospitals with fewer than 10 UKAs annually [5]. It is uncertain how these changes in hospital volume affected the UKA survival rate, and more research is needed to find the best UKA volume at the surgeon or hospital level. Based on our data, there is no obvious reason why survival of UKA did not improve comparably to that of TKA. The Oxford $^{\circledR}$ Phase 3 (Biomet) was the dominant implant during both periods, and lack of improvement in design may be one of the reasons why UKA survival did not improve. The Tricon ${ }^{\mathrm{TM}}$ and GENESIS I implants have shown a higher risk of revision in the Norwegian population [44], and these implants were not used during Period 2, which also might have contributed to improvement in TKA survival. However, improvement in implant survival is likely multifactorial and a combination of patient selection, improved implants and techniques, education, and procedure volume. Many of these factors are not detectable from registry data, but this study generates important questions for future research.

\section{Changes in Revision Causes}

TKA and UKA declined in late revisions resulting from polyethylene wear/breakage, which also was found by Thiele et al. [70]. Paxton et al. [56] found a similar risk of revision for highly crosslinked polyethylene compared with conventional polyethylene. Highly crosslinked polyethylene is rarely used in Norway in knee arthroplasty $(8 \%$ in 2013-2015) [69], indicating improvements in conventional polyethylene and polishing, sterilization, and locking mechanisms [37, 39, 68]. The risk of revision resulting from malalignment was unchanged for TKA and UKA. Computer navigation improves alignment in TKA and UKA [28, 47, 66] and also has resulted in improved survival and fewer revisions owing to malalignment [17, 19]. The use of computer navigation has declined in Norway [69], but more extensive use may address this problem. It is 
concerning that the risk of TKA revisions resulting from infection was increased during the early postoperative time in Period 2, with a fivefold increase at 0 to 1.5 months. A similar trend was described in hip arthroplasties in Scandinavia $[14,15,63]$. These studies indicate a trend toward higher awareness and more-aggressive treatment for prosthetic infections with earlier removal of components rather than protracted antibiotic treatment, which is consistent with the current approach to infected arthroplasties [26]. Higher awareness and an improved reporting rate of periprosthetic infections may explain some of the increased infection rate during Period 2. It also could be caused by an improved reporting rate or more-resistant bacteria [42]. Early surgical treatment could be one of the reasons that risk of late revision ( $>1$ year) resulting from infection was reduced during Period 2, but this should be investigated in future studies including multiple revisions. Revisions resulting from unexplained pain were reduced in TKA, but unexplained pain remains a common revision cause for TKA and UKA. Some of the reduction in unexplained pain is most likely caused by a reclassification to "progression of osteoarthritis", as this was introduced as a separate revision cause in the registration form from 2011. Patients with pain after knee arthroplasty should be evaluated systematically according to diagnostic algorithms, and conservative treatment is recommended if no reason for the pain is found [18, 32, 52].

\section{Changes in Patient and Implant Characteristics}

We found that patients in Period 2 were younger and more often men. Previous studies have found that young age and male sex increase the risk of revision [36, 55, 62]. This was adjusted for in the statistical analyses of revision causes, but could cause a reduction in the unadjusted survival rate in Period 2 for TKA and UKA. Despite a decline in Period 2 , aseptic loosening is still a common failure mechanism for TKA [16, 64] and UKA [11, 13]. We found a decreased risk of revision resulting from loosening of the femoral component of TKAs, whereas loosening of the tibial component was unchanged. There was also an increase in use of mobile bearing implants during Period 2, mainly the LCS $^{\circledR}$ COMPLETE (DePuy). Mobile bearing implants have shown a higher revision rate in previous registry studies [12, 30, 48, 49] and the LCS ${ }^{\circledR}$ COMPLETE had a higher revision rate in registry studies in Norway and Kaiser Permanente, especially resulting from aseptic loosening of the tibial component $[29,55]$. The increased use of the LCS ${ }^{\circledR}$ COMPLETE during Period 2 may explain the lack of improvement of aseptic loosening of the tibial component and also could affect the overall revision rate. A previous study from the NAR found a high risk of revision resulting from patella dislocation for the Duracon $^{\text {TS }}$ (Stryker) and AGC Universal (Biomet) TKA prostheses [29], and a shift to more patella-friendly designs may explain the reduction in patella dislocations and unexplained pain. The use of patella resurfacing was lower in Period 2, probably owing to previous studies showing no difference in functional outcomes and risk of revision for resurfaced and nonresurfaced TKAs in Norway, the United Kingdom, and Sweden [24, 35, 43, 44, 61]. However, patella-resurfaced implants had a lower risk of revision in meta-analyses [10, 54] and improved functional outcomes in a recent Norwegian randomized controlled trial for NexGen ${ }^{\circledR}$ cruciate-retaining prosthesis [3]. The threshold for revising a TKA resulting from unexplained pain may be lower for nonresurfaced implants, but secondary patella resurfacing gives little improvement in pain and satisfaction [38, 71] and should not be recommended for most patients. Based on our study, it is uncertain whether the use of nonresurfaced TKAs affected the survival rate or causes of revision. The Oxford ${ }^{\circledR}$ Phase 3 (Biomet) and Oxford ${ }^{\circledR}$ Partial Knee (Zimmer Biomet) were the most-used UKA implants. A study from the Swedish arthroplasty register found that the Oxford ${ }^{\circledR}$ meniscal-bearing knee implant had a higher risk of revision in low-volume hospitals and suggested that this implant was sensitive to hospital volume resulting from its technical demands [60]. High use of this technically demanding implant may partly explain the lack of improvement in UKA survival, especially if used in low-volume hospitals.

\section{Conclusion}

We found that survival improved for TKA during the last decade, but not for UKA, and survivorship for UKAs remains rather dramatically lower than that observed for TKA. The risk of revision resulting from femoral aseptic loosening, polyethylene wear/breakage, patella dislocation, and pain was reduced for TKA, but there was an increased risk of early revision resulting from infection. For TKA, the overall risk of revision was improved during Period 2 for cemented and hybrid implants, but not for uncemented implants. Cemented or hybrid fixation may be the safest choice, at least for patients with additional risk factors for failure. UKA had a reduced risk of revision attributable to aseptic loosening, polyethylene wear/breakage, and periprosthetic fracture, but revision resulting from progression of osteoarthritis is still a major problem. The decision to perform a UKA should be made with the explicit awareness that its survivorship is substantially inferior to that of a TKA; any perceived advantages of UKA should be balanced against this issue of durability. This study shows that there is still substantial room for 
improvement in prosthesis survival, and the priorities of future studies and technologic advances should focus on the most-common revision causes: infection, tibial aseptic loosening, malalignment, instability, unexplained pain, and progression of osteoarthritis.

Acknowledgments We thank all prosthesis surgeons in Norway for reporting data to the Norwegian Arthroplasty Register and the patients who gave their consent to be included in the Norwegian Arthroplasty Register database.

\section{References}

1. AOA Australian Orthopaedic Association National Joint Replacement Registry. Annual Report 2015: Hip and Knee Arthroplasty. Available at: https://aoanjrr.sahmri.com/en/annualreports-2015. Accessed February 27, 2017.

2. Arthursson AJ, Furnes O, Espehaug B, Havelin LI, Söreide, JA. Validation of data in the Norwegian Arthroplasty Register and the Norwegian Patient Register: 5,134 primary total hip arthroplasties and revisions operated at a single hospital between 1987 and 2003. Acta Orthop. 2005;76:823-828.

3. Aunan E, Naess G, Clarke-Jenssen J, Sandvik L, Kibsgard TJ. Patellar resurfacing in total knee arthroplasty: functional outcome differs with different outcome scores: a randomized, double-blind study of 129 knees with 3 years of follow-up. Acta Orthop. 2016;87:158-164.

4. Badawy M, Espehaug B, Indrekvam K, Engesaeter LB, Havelin LI, Furnes O. Influence of hospital volume on revision rate after total knee arthroplasty with cement. J Bone Joint Surg Am. 2013;95:e131.

5. Badawy M, Espehaug B, Indrekvam K, Havelin LI, Furnes O. Higher revision risk for unicompartmental knee arthroplasty in low-volume hospitals. Acta Orthop. 2014;85:342-347.

6. Bozic KJ, Kamath AF, Ong K, Lau E, Kurtz S, Chan V, Vail TP, Rubash H, Berry DJ. Comparative epidemiology of revision arthroplasty: failed THA poses greater clinical and economic burdens than failed TKA. Clin Orthop Relat Res. 2015;473:21312138.

7. Bozic KJ, Lau E, Kurtz S, Ong K, Rubash H, Vail TP, Berry DJ. Patient-related risk factors for periprosthetic joint infection and postoperative mortality following total hip arthroplasty in Medicare patients. J Bone Joint Surg Am. 2012;94:794-800.

8. Canadian Institute for Health Information. Hip and Knee Replacements in Canada: Canadian Joint Replacement Registry 2015 Annual Report. Available at: https://secure.cihi.ca/free products/CJRR_2015_Annual_Report_EN.pdf. Accessed February 28, 2017.

9. Carr AJ, Robertsson O, Graves S, Price AJ, Arden NK, Judge A, Beard DJ. Knee replacement. Lancet. 2012;379:1331-1340.

10. Chen K, Li G, Fu D, Yuan C, Zhang Q, Cai Z. Patellar resurfacing versus nonresurfacing in total knee arthroplasty: a metaanalysis of randomised controlled trials. Int Orthop. 2013;37:1075-1083.

11. Citak M, Cross MB, Gehrke T, Dersch K, Kendoff D. Modes of failure and revision of failed lateral unicompartmental knee arthroplasties. Knee. 2015;22:338-340.

12. Comfort T, Baste V, Froufe MA, Namba R, Bordini B, Robertsson O, Cafri G, Paxton E, Sedrakyan A, Graves S. International comparative evaluation of fixed-bearing non-posterior-stabilized and posterior-stabilized total knee replacements. J Bone Joint Surg Am. 2014;96(suppl 1):65-72.
13. Craik JD, El Shafie SA, Singh VK, Twyman RS. Revision of unicompartmental knee arthroplasty versus primary total knee arthroplasty. J Arthroplasty. 2015;30:592-594.

14. Dale H, Fenstad AM, Hallan G, Havelin LI, Furnes O, Overgaard S, Pedersen AB, Karrholm J, Garellick G, Pulkkinen P, Eskelinen A, Makela K, Engesaeter LB. Increasing risk of prosthetic joint infection after total hip arthroplasty. Acta Orthop. 2012;83:449458.

15. Dale H, Hallan G, Espehaug B, Havelin LI, Engesaeter LB. Increasing risk of revision due to deep infection after hip arthroplasty. Acta Orthop. 2009;80:639-645.

16. Dalury DF, Pomeroy DL, Gorab RS, Adams MJ. Why are total knee arthroplasties being revised? J Arthroplasty. 2013;28(8 suppl):120-121.

17. de Steiger RN, Liu YL, Graves SE. Computer navigation for total knee arthroplasty reduces revision rate for patients less than sixtyfive years of age. J Bone Joint Surg Am. 2015;97:635-642.

18. Djahani O, Rainer S, Pietsch M, Hofmann S. Systematic analysis of painful total knee prosthesis: a diagnostic algorithm. Arch Bone Jt Surg. 2013;1:48-52.

19. Dyrhovden GS, Fenstad AM, Furnes O, Gothesen O. Survivorship and relative risk of revision in computer-navigated versus conventional total knee replacement at 8-year follow-up. Acta Orthop. 2016:87:592-599.

20. Espehaug B, Furnes O, Havelin LI, Engesæter LB, Vollset SE, Kindseth O. Registration completeness in the Norwegian Arthroplasty Register. Acta Orthop. 2006;77:49-56.

21. Fehring TK, Odum SM, Masonis JL, Springer BD. Early failures in unicondylar arthroplasty. Orthopedics. 2010;33:11.

22. Fine JP, Gray RJ. A proportional hazards model for the subdistribution of a competing risk. J Am Stat Assoc. 1999;94:496-509.

23. Furnes O. Hip and knee replacement in Norway 1987-2000. The Norwegian Arthroplasty Register. Available at: http://nrlweb. ihelse.net/Forskning/Publikasjoner/Hip_and_knee_replacement_ in_Norway_1987-2000.pdf. Accessed September 19, 2016.

24. Furnes O, Espehaug B, Lie SA, Vollset SE, Engesaeter LB, Havelin LI. Early failures among 7,174 primary total knee replacements: a follow-up study from the Norwegian Arthroplasty Register 1994-2000. Acta Orthop Scand. 2002;73:117129.

25. Furnes O, Espehaug B, Lie SA, Vollset SE, Engesaeter LB, Havelin LI. Failure mechanisms after unicompartmental and tricompartmental primary knee replacement with cement. $J$ Bone Joint Surg Am. 2007;89:519-525.

26. Gehrke T, Alijanipour P, Parvizi J. The management of an infected total knee arthroplasty. Bone Joint J. 2015;97(10 suppl A):20-29.

27. EPRD Endoprotesenregister Deutschland. Endoprothesenregister Deutschland (EPRD). Statusbericht 2014. Mit Sicherheit mehr Qualität. Available at: http://www.eprd.de/fileadmin/user_upload/ Dateien/Publikationen/Berichte/EPRD_Statusberich_2014_FINAL_ Online_Version.pdf. Accessed February 28, 2017.

28. Gothesen O, Espehaug B, Havelin LI, Petursson G, Hallan G, Strom E, Dyrhovden G, Furnes O. Functional outcome and alignment in computer-assisted and conventionally operated total knee replacements: a multicentre parallel-group randomised controlled trial. Bone Joint J. 2014;96:609-618.

29. Gothesen O, Espehaug B, Havelin LI, Petursson G, Lygre S, Ellison P, Hallan G, Furnes O. Survival rates and causes of revision in cemented primary total knee replacement: a report from the Norwegian Arthroplasty Register 1994-2009. Bone Joint J. 2013;95:636-642.

30. Graves S, Sedrakyan A, Baste V, Gioe TJ, Namba R, Martinez Cruz O, Stea S, Paxton E, Banerjee S, Isaacs AJ, Robertsson O. International comparative evaluation of knee replacement with 
fixed or mobile-bearing posterior-stabilized prostheses. $J$ Bone Joint Surg Am. 2014;96(suppl 1):59-64.

31. Greidanus NV, Peterson RC, Masri BA, Garbuz DS. Quality of life outcomes in revision versus primary total knee arthroplasty. $J$ Arthroplasty. 2011;26:615-620.

32. Hofmann S, Seitlinger G, Djahani O, Pietsch M. The painful knee after TKA: a diagnostic algorithm for failure analysis. Knee Surg Sports Traumatol Arthrosc. 2011;19:1442-1452.

33. Inacio MC, Paxton EW, Dillon MT. Understanding orthopaedic registry studies: a comparison with clinical studies. J Bone Joint Surg Am. 2016;98:e3.

34. Kalson NS, Borthwick LA, Mann DA, Deehan DJ, Lewis P, Mann C, Mont MA, Morgan-Jones R, Oussedik S, Williams FM, Toms A, Argenson JN, Bellemans J, Bhave A, Furnes O, Gollwitzer H, Haddad FS, Hofmann S, Krenn V. International consensus on the definition and classification of fibrosis of the knee joint. Bone Joint J. 2016;98:1479-1488.

35. KAT Trial Group, Johnston L, MacLennan G, McCormack K, Ramsay C, Walker A. The Knee Arthroplasty Trial (KAT) design features, baseline characteristics, and two-year functional outcomes after alternative approaches to knee replacement. $J$ Bone Joint Surg Am. 2009;91:134-141.

36. Kurtz SM, Ong KL, Schmier J, Mowat F, Saleh K, Dybvik E, Karrholm J, Garellick G, Havelin LI, Furnes O, Malchau H, Lau E. Future clinical and economic impact of revision total hip and knee arthroplasty. J Bone Joint Surg Am. 2007;89(suppl 3):144151.

37. Lapaj L, Mroz A, Kokoszka P, Markuszewski J, Wendland J, Helak-Lapaj C, Kruczynski J. Peripheral snap-fit locking mechanisms and smooth surface finish of tibial trays reduce backside wear in fixed-bearing total knee arthroplasty. Acta Orthop. 2017;88:62-69.

38. Leta TH, Lygre SH, Skredderstuen A, Hallan G, Gjertsen JE, Rokne B, Furnes O. Secondary patella resurfacing in painful nonresurfaced total knee arthroplasties : a study of survival and clinical outcome from the Norwegian Arthroplasty Register (1994-2011). Int Orthop. 2016;40:715-722.

39. Levine RA, Lewicki KA, Currier JH, Mayor MB, Van Citters DW. Contribution of micro-motion to backside wear in a fixed bearing total knee arthroplasty. J Orthop Res. 2016;34:19351940.

40. Liddle AD, Pandit H, Judge A, Murray DW. Effect of surgical caseload on revision rate following total and unicompartmental knee replacement. J Bone Joint Surg Am. 2016;98:1-8.

41. Lombardi AV Jr, Berend KR, Adams JB. Why knee replacements fail in 2013: patient, surgeon, or implant? Bone Joint J. 2014;96(11 suppl A):101-104.

42. Lutro O, Langvatn H, Dale H, Schrama JC, Hallan G, Espehaug B, Sjursen H, Engesaeter LB. Increasing resistance of coagulasenegative staphylococci in total hip arthroplasty infections: 278 THA-revisions due to infection reported to the Norwegian Arthroplasty Register from 1993 to 2007. Adv Orthop. 2014;2014:580359. doi:10.1155/2014/580359.

43. Lygre SH, Espehaug B, Havelin LI, Vollset SE, Furnes O. Does patella resurfacing really matter? Pain and function in 972 patients after primary total knee arthroplasty. Acta Orthop. 2010;81:99-107.

44. Lygre SH, Espehaug B, Havelin LI, Vollset SE, Furnes O. Failure of total knee arthroplasty with or without patella resurfacing. Acta Orthop. 2011;82:282-292.

45. Manley M, Ong K, Lau E, Kurtz SM. Total knee arthroplasty survivorship in the United States Medicare population: effect of hospital and surgeon procedure volume. $J$ Arthroplasty. 2009;24:1061-1067.

46. Murray DW, Frost SJ. Pain in the assessment of total knee replacement. J Bone Joint Surg Br. 1998;80:426-431.
47. Nair R, Tripathy G, Deysine GR. Computer navigation systems in unicompartmental knee arthroplasty: a systematic review. Am J Orthop (Belle Mead NJ). 2014;43:256-261.

48. Namba R, Graves S, Robertsson O, Furnes O, Stea S, Puig-Verdie L, Hoeffel D, Cafri G, Paxton E, Sedrakyan A. International comparative evaluation of knee replacement with fixed or mobile non-posterior-stabilized implants. $J$ Bone Joint Surg Am. 2014;96(suppl 1):52-58.

49. Namba RS, Inacio MC, Paxton EW, Robertsson O, Graves SE. The role of registry data in the evaluation of mobile-bearing total knee arthroplasty. J Bone Joint Surg Am. 2011;93(suppl 3):4850.

50. NJR National Joint Registry. 12th Annual Report 2015. National Joint Registry for England, Wales, Northern Ireland and the Isle of Man. Available at: http://www.njrcentre.org.uk/njrcentre/Por tals/0/Documents/England/Reports/12th\%20annual\%20report/NJ R\%20Online\%20Annual\%20Report\%202015.pdf. Accessed February $28,2017$.

51. NZOA New Zealand Orthopaedic Association. The New Zealand Joint Registry. Sixteen Year Report January 1999 to December 2014. Available at: http://nzoa.org.nz/system/files/Web_ DH7657_NZJR2014Report_v4_12Nov15.pdf. Accessed February 28, 2017.

52. Park CN, White PB, Meftah M, Ranawat AS, Ranawat CS Diagnostic algorithm for residual pain after total knee arthroplasty. Orthopedics. 2016:39:e246-252.

53. Patel A, Pavlou G, Mujica-Mota RE, Toms AD. The epidemiology of revision total knee and hip arthroplasty in England and Wales: a comparative analysis with projections for the United States: a study using the National Joint Registry dataset. Bone Joint J. 2015;97:1076-1081.

54. Pavlou G, Meyer C, Leonidou A, As-Sultany M, West R, Tsiridis E. Patellar resurfacing in total knee arthroplasty: does design matter? A meta-analysis of 7075 cases. J Bone Joint Surg Am. 2011;93:1301-1309.

55. Paxton EW, Furnes O, Namba RS, Inacio MC, Fenstad AM, Havelin LI. Comparison of the Norwegian knee arthroplasty register and a United States arthroplasty registry. J Bone Joint Surg Am. 2011;93(suppl 3):20-30.

56. Paxton EW, Inacio MC, Kurtz S, Love R, Cafri G, Namba RS. Is there a difference in total knee arthroplasty risk of revision in highly crosslinked versus conventional polyethylene? Clin Orthop Relat Res. 2015;473:999-1008.

57. Pearse AJ, Hooper GJ, Rothwell A, Frampton C. Survival and functional outcome after revision of a unicompartmental to a total knee replacement: the New Zealand National Joint Registry. $J$ Bone Joint Surg Br. 2010;92:508-512.

58. Ranstam J, Karrholm J, Pulkkinen P, Makela K, Espehaug B, Pedersen AB, Mehnert F, Furnes O; Nara study group. Statistical analysis of arthroplasty data: II. Guidelines. Acta Orthop. 2011;82:258-267.

59. Robertsson O, Bizjajeva S, Fenstad AM, Furnes O, Lidgren L, Mehnert F, Odgaard A, Pedersen AB, Havelin LI. Knee arthroplasty in Denmark, Norway and Sweden: a pilot study from the Nordic Arthroplasty Register Association. Acta Orthop. 2010;81:82-89.

60. Robertsson O, Knutson K, Lewold S, Lidgren L. The routine of surgical management reduces failure after unicompartmental knee arthroplasty. J Bone Joint Surg Br. 2001;83:45-49.

61. Robertsson O, W-Dahl A, Lidgren L, Sundberg M. Annual Report 2015. The Swedish Knee Arthroplasty Register. Available at: https://www.researchgate.net/publication/285400641_Annual_ report_2015_-_The_Swedish_Knee_Arthroplasty_Register. Accessed February 28, 2017.

62. Santaguida PL, Hawker GA, Hudak PL, Glazier R, Mahomed NN, Kreder HJ, Coyte PC, Wright JG. Patient characteristics 
affecting the prognosis of total hip and knee joint arthroplasty: a systematic review. Can J Surg. 2008;51:428-436.

63. Schrama JC, Fenstad AM, Dale H, Havelin L, Hallan G, Overgaard S, Pedersen AB, Karrholm J, Garellick G, Pulkkinen $\mathrm{P}$, Eskelinen A, Makela $\mathrm{K}$, Engesaeter LB, Fevang BT. Increased risk of revision for infection in rheumatoid arthritis patients with total hip replacements. Acta Orthop. 2015;86:469-476.

64. Schroer WC, Berend KR, Lombardi AV, Barnes CL, Bolognesi MP, Berend ME, Ritter MA, Nunley RM. Why are total knees failing today? Etiology of total knee revision in 2010 and 2011. $J$ Arthroplasty. 2013;28(8 suppl):116-119.

65. Sharkey PF, Lichstein PM, Shen C, Tokarski AT, Parvizi J. Why are total knee arthroplasties failing today: has anything changed after 10 years? J Arthroplasty. 2014;29:1774-1778.

66. Shi J, Wei Y, Wang S, Chen F, Wu J, Huang G, Chen J, Wei L, Xia J. Computer navigation and total knee arthroplasty. Orthopedics. 2014;37:e39-43.

67. Skou ST, Roos EM, Laursen MB, Rathleff MS, Arendt-Nielsen L, Simonsen O, Rasmussen S. A randomized, controlled trial of total knee replacement. N Engl J Med. 2015;373:1597-1606.
68. Teeter MG, Lanting BA, Shrestha KR, Howard JL, Vasarhelyi EM. Contribution of surface polishing and sterilization method to backside wear in total knee arthroplasty. J Arthroplasty. 2015;30:2320-2322.

69. The Norwegian Arthroplasty Register. Report June 2016, Norwegian National Advisoral Unit on Arthroplasty and Hip Fractures. Available at: http://nrlweb.ihelse.net/Rapporter/ Report2016_english.pdf. Accessed March 1, 2017.

70. Thiele K, Perka C, Matziolis G, Mayr HO, Sostheim M, Hube R. Current failure mechanisms after knee arthroplasty have changed: polyethylene wear is less common in revision surgery. $J$ Bone Joint Surg Am. 2015;97:715-720.

71. van Jonbergen HP, Boeddha AV, M van Raaij JJ. Patient satisfaction and functional outcomes following secondary patellar resurfacing. Orthopedics. 2016;39:e850-856.

72. Watts CD, Houdek MT, Wagner ER, Abdel MP, Taunton MJ. Insulin dependence increases the risk of failure after total knee arthroplasty in morbidly obese patients. $J$ Arthroplasty. 2016;31:256-259.

73. Zimmerli W, Trampuz A, Ochsner PE. Prosthetic-joint infections. N Engl J Med. 2004;351:1645-1654. 